DANILO HADDAD JAFET

Responsabilidade Civil pela Perda de uma Chance: Seriedade das Chances Perdidas e Quantificação do Dano

\author{
Dissertação de Mestrado \\ Orientador: Professor Associado Dr. José Fernando Simão
}

UNIVERSIDADE DE SÃO PAULO

FACULDADE DE DIREITO

SÃO PAULO - SP

2018 

DANILO HADDAD JAFET

\title{
Responsabilidade Civil pela Perda de uma Chance: Seriedade das Chances Perdidas e Quantificação do Dano
}

Dissertação apresentada à Banca Examinadora do Programa de Pós-Graduação em Direito, da Faculdade de Direito da Universidade de São Paulo, como exigência parcial para obtenção do título de Mestre em Direito, na área de concentração Direito Civil, sob orientação do Professor Associado Dr. José Fernando Simão.

\author{
UNIVERSIDADE DE SÃO PAULO \\ FACULDADE DE DIREITO \\ SÃO PAULO - SP \\ 2018
}


Haddad Jafet, Danilo

Responsabilidade Civil pela Perda de uma Chance: Seriedade das Chances Perdidas e Quantificação do Dano / Danilo Haddad Jafet ; orientador José Fernando Simão -- São Paulo, 2018.

210

Dissertação (Mestrado - Programa de Pós-Graduação em Direito Civil) Faculdade de Direito, Universidade de São Paulo, 2018.

1. Responsabilidade civil. 2. Perda de uma chance. 3. Dano indenizável. 4. Seriedade. 5. Quantificação. I. Simão, José Fernando, orient. II. Título.| 


\section{AGRADECIMENTOS}

A elaboração e a conclusão exitosa de um trabalho acadêmico no âmbito da pós-graduação não dependem apenas e exclusivamente do autor. Neste caso, não foi diferente. Algumas pessoas exerceram papéis determinantes para que este trabalho chegasse ao final.

Agradeço, primeiramente, ao Professor José Fernando Simão, que, ao aceitar minha orientação, possibilitou que uma mera esperança subjetiva de obtenção do título de Mestre em Direito Civil se transformasse em uma chance séria e real de alcançar o árduo intento. Também foram valiosas as reuniões que fizemos, suas correções e sugestões de inclusões no trabalho, bem como os conselhos que transpassaram a mera revisão da dissertação.

Pelas referências de pessoas e profissionais do Direito sérios, dedicados, talentosos e bem sucedidos, que serviram de inspiração para meu ingresso na carreira jurídica e sempre estiveram ao meu lado, dando incondicional incentivo em todas as etapas de minha formação acadêmica, agradeço aos meus pais Cristina Haddad e Sergio Jafet.

Aproveito este espaço para expressar minha gratidão também ao amigo Cesar Cordaro, que admiro pela inteligência, pela erudição e pela incansável sede por conhecimento. Junto com meus pais, Cesar fez a revisão ortográfica e gramatical desta dissertação.

Sou igualmente grato ao grande amigo Giovani G. Gianellini, que me serviu como apoio ao longo de todo o curso de Mestrado. Giovani sempre me incentivou, ofereceu ajuda e deu-me boas ideias de como contornar problemas enfrentados neste longo caminho. As várias conversas que tivemos e os profundos conselhos que dele recebi nos últimos três anos foram essenciais para que, hoje, esta dissertação esteja concluída.

Neste trabalho, foram abordados alguns conceitos que envolvem as teorias estatística e probabilística, estranhas à grande maioria dos profissionais do Direito, que geralmente não dominam com maestria a ciência matemática. Para me certificar do correto tratamento e da aplicação técnica de referidos conceitos, tive a sorte de contar com a ajuda providencial do Professor Rafael Bassi Stern, que, de forma extremamente solícita e voluntária, analisou trechos nucleares da dissertação e deu-me a segurança de que as noções de estatística e probabilística foram expostas de modo apurado. Uma das conversas que tive com o Professor Rafael me deu a oportunidade de fazer algumas reflexões que considero bastante importantes para algumas conclusões parciais alcançadas. 
Não posso deixar de agradecer aos Professores Francisco Paulo de Crescenzo Marino e Marco Fábio Morsello, que integraram minha banca de qualificação e, na oportunidade, fizeram valiosíssimas sugestões que, uma vez seguidas, contribuíram muito para o aprimoramento técnico e para o enriquecimento deste trabalho.

Finalmente, agradeço a algumas pessoas que, ainda que de forma indireta, participaram comigo desta jornada. São elas: Priscila Haddad Jafet, Lara Japiassú, Lino Araújo e Rafael Bresciani. 


\section{RESUMO}

Haddad Jafet, Danilo. Responsabilidade Civil pela Perda de uma Chance: Seriedade das Chances Perdidas e Quantificação do Dano 2018. Mestrado. Faculdade de Direito, Universidade de São Paulo, São Paulo, 2018.

Esta dissertação de mestrado tem como objetivo fulcral o estudo aprofundado da seriedade das chances perdidas e da quantificação do dano na responsabilidade civil pela perda de uma chance. Feita uma breve síntese do nascimento do instituto da perda de uma chance nos principais ordenamentos jurídicos que tratam do tema, a etapa seguinte consiste em uma análise crítica do dano decorrente das chances perdidas, que passa pelo estudo da sua natureza jurídica e das modalidades de perda da chance. O núcleo do trabalho compreende duas etapas: (i) primeiramente, definir a chance séria e real, o que passa pela fixação de critérios para estabelecer a seriedade das chances perdidas; e, na sequência, (ii) abordar os diferentes métodos de quantificação do dano decorrente da perda de uma chance para verificar qual é a forma mais adequada de se alcançar o valor do dano sofrido pela vítima. $\mathrm{Na}$ parte final do trabalho, são abordadas algumas técnicas que contribuem para uma melhor aplicação do instituto em situações específicas.

Palavras-chave: Responsabilidade civil. Perda de uma chance. Dano indenizável. Seriedade. Quantificação. Nexo causal. 



\begin{abstract}
Haddad Jafet, Danilo. Loss of a Chance in Tort Law: Substantial Chances and Valuation of Lost Chances. 2018. Master. Law School, University of São Paulo, São Paulo, 2018.

The main purpose of this Master's thesis is to perform a further detailed study concerning the substantiality of lost chances, as well as valuation of the damages regarding lost chances in Tort Law. Following a brief synthesis of the origins of the loss of a chance theory in the main legal systems dealing with the subject, the next step consists of a critical analysis of the damage resulting from the lost chances, which comprehends the study of legal nature of the damage and different species of lost chances. The main goal of this thesis involves two stages: (i) firstly, constructing a definition of a substantial chance and establishing the necessary criteria to find the substantiality of a lost chance; and, secondly, (ii) addressing the different methods of valuating damage arising from the loss of a chance, in order to ascertain the most appropriate way to determine the value of the loss. The last part of this work explores some techniques that may contribute to a better application of the loss of a chance theory in some specific situations.
\end{abstract}

Key-words: Tort law. Loss of a chance. Compensable loss. Substantiality. Valuation. Causation. 



\section{SUMÁRIO}

INTRODUÇÃO.

1. O NASCIMENTO DA TEORIA DA PERDA DE UMA CHANCE ......................... 17

1.1. Perda da chance no direito norte-americano .......................................................20

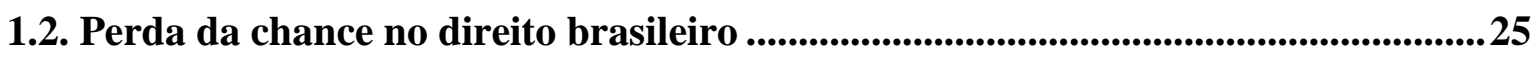

2. O DANO DECORRENTE DA PERDA DE UMA CHANCE ..................................31

2.1. A visão tradicional norte-americana em contraposição ao modelo brasileiro .......31

2.1.1. Os padrões de causalidade tradicionais nos Estados Unidos.............................. 33

2.1.2. Críticas à visão tradicional norte-americana..................................................37

2.2. As presunçø̃es de causalidade ........................................................................................................38

2.3. Modalidades de perda de uma chance ......................................................................44

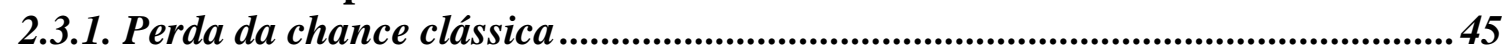

2.3.2. Perda da chance de evitar um prejuízo já ocorrido ............................................. 47

2.3.2.1. A teoria majoritária no direito francês: tudo ou nada ................................... 50

2.3.2.2. A adoção da causalidade parcial para ambas as modalidades de perda da

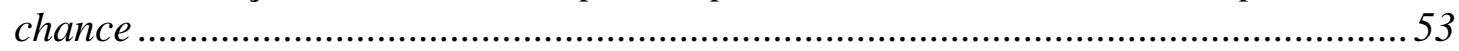

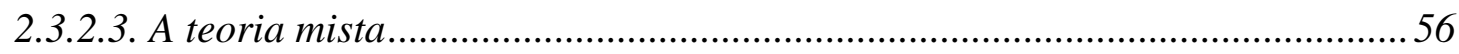

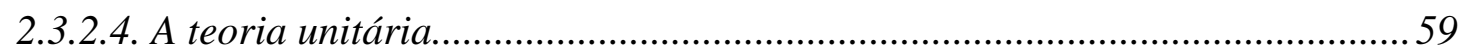

2.4. Natureza jurídica do dano ....................................................................................................65

2.4.1. A chance perdida como dano patrimonial ...........................................................66 66

2.4.1.1. A chance perdida como lucro cessante: impossibilidade .............................6 67

2.4.1.2. A chance perdida como dano emergente: pertinência ................................... 70

2.4.1.3. A chance perdida como nova modalidade de dano: desnecessidade ............. 72

2.4.2. A chance perdida como dano extrapatrimonial.......................................................75

2.4.2.1. A chance perdida como mero agregador de dano moral .............................. 75

2.4.2.2. A compreensão acertada da chance perdida como dano extrapatrimonial... 78

\section{A SERIEDADE DAS CHANCES PERDIDAS ......................................................}

3.1. Perda da chance $x$ criação de risco futuro .............................................................

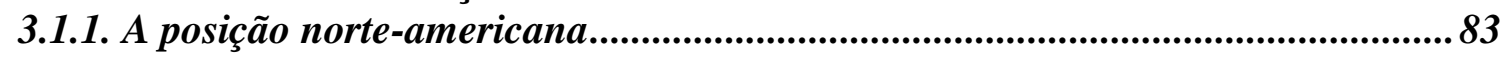

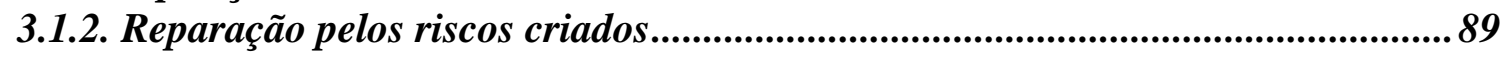

3.1.3. Os danos indenizáveis a partir da criação de riscos .......................................... 92

3.2. A fixação de limite percentual definidor da seriedade da chance ..........................94

3.3. A definitividade da chance perdida........................................................................................101

3.4. A importância do lapso temporal entre o evento danoso e a vantagem perdida 105

3.5. Chances estatísticas $x$ chances pessoais 
3.6. Probabilidades de primeira e segunda ordens

3.7. O princípio da conjunção no estabelecimento do nexo causal

3.8. Erros na aplicação da perda da chance na seara médica 133

4. A QUANTIFICAÇÃO DO DANO 137

4.1. O princípio da conjunção na quantificação do dano ..................................................140

4.2. Métodos para quantificação do dano ...................................................................142

4.2.1. O método da proporcionalidade

4.2.2. $O$ método da proporcionalidade relativa.

4.2.3. O método da quantificação da perda da chance em class actions

4.2.4. $O$ método do risco atribuído

4.2.5. O método da discricionariedade.

4.2.6. O método bifásico: a forma mais adequada de quantificar o dano. 168

4.3. Subsidiariamente: $o$ recurso à equidade 171

\section{TÉCNICAS CONTRIBUTIVAS PARA UMA MELHOR APLICAÇÃO DO} INSTITUTO

5.1. Perda da chance de ascender na carreira .............................................................178

5.2. Jurimetria e a negligência do advogado ...............................................................182

5.3. Perda da chance no seguro: aplicação em prol do responsável por indenizar.... 184

CONCLUSÃO 193

BIBLIOGRAFIA 


\section{INTRODUÇÃO}

A responsabilidade civil é um tema clássico do Direito Civil, que teve origem no direito romano, mas que permanece extremamente atual, ainda na pós-modernidade. Aliás, podese dizer, sem exagero algum, que sua utilidade prática cresce no mesmo ritmo com o qual se desenvolvem as relações sociais.

Esse ramo do direito obrigacional cuida do dever de reparação dos danos causados pela violação de deveres e obrigações jurídicas. O Código Civil dedica ao tema o título IX, intitulado Da Responsabilidade Civil, no qual se situa o artigo 927 que, em linhas gerais, traz a definição do instituto, ao dispor que "todo aquele que, por ato ilícito, causar dano a outrem, tem a obrigação de repará-lo". Sergio Cavalieri Filho sintetiza muito bem o conceito ao dizer que "responsabilidade civil é um dever jurídico sucessivo que surge para recompor o dano decorrente da violação de um dever jurídico originário".

A teoria clássica situava a responsabilidade civil no campo do direito privado. $\mathrm{O}$ direito do século XIX, que dava as bases sustentadoras das sociedades liberais, destinava ao instituto um caráter fortemente individualista. Desse modo, embora já separada da responsabilidade penal, a responsabilidade civil pressupunha a existência de ilicitude. Somente era responsabilizado o indivíduo que agisse com culpa, elemento essencial para gerar o dever de reparação. Entrementes, as mudanças advindas da Revolução Industrial foram sentidas em todos os âmbitos das relações sociais, inclusive no Direito.

O avanço tecnológico, o crescimento acelerado da densidade populacional, a diversidade múltipla das novas formas de trabalho e produção e a intensificação da complexidade das relações sociais contribuíram, imensamente, para o surgimento de inúmeras novas ameaças à segurança pessoal dos indivíduos. Aliado a isso, em muitas situações, mostrava-se impossível provar a causa dos atos lesivos e, portanto, imputar culpa a alguém, o que significava deixar de indenizar as vítimas, muitas vezes desprovidas de recursos, que passavam a suportar os prejuízos sofridos.

Foi nesse contexto que surgiu a teoria objetiva da responsabilidade civil, para a qual a culpa deixava de ser elemento essencial para a responsabilização do agente. Assim,

\footnotetext{
${ }^{1}$ CAVALIERI FILHO, Sergio. Programa de Responsabilidade Civil. 9. ed. revista e ampliada, São Paulo: Atlas, 2010, p.2.
} 
passou-se a responsabilizar determinados agentes pelos danos decorrentes do simples exercício de determinadas atividades, consideradas de risco, independentemente da verificação do elemento culpa. Nesses casos, o estudo deveria se afastar da análise da culpabilidade do causador do dano, para "ajustar seu foco na análise objetiva de reparação da vítima". ${ }^{2}$ Essa foi, sem dúvida, a maior evolução que o instituto já sofreu ao longo da História. Assim, embora não exista responsabilidade sem dano ${ }^{3}$, existe responsabilidade sem culpa.

Por outro lado, os fenômenos políticos, econômicos, sociais e ambientais mais contemporâneos continuaram a exigir mudanças para que o Direito permanecesse acompanhando as transformações experimentadas no campo das relações humanas. Ao longo dos últimos séculos, foi grande a demanda por novas hipóteses de responsabilidade civil - como a responsabilidade do segurador, a responsabilidade das instituições bancárias, a responsabilidade dos grupos, a responsabilidade da Administração Pública, entre outras.

Se em sua evolução histórica a responsabilidade civil se ocupava da figura do causador do dano, a realidade imposta pela dinamicidade dos avanços sociais, das mais variadas ordens, fez com que a vítima do dano se tornasse protagonista na relação jurídica instaurada. ${ }^{4} \mathrm{O}$ objetivo central da responsabilidade civil passou a ser a reparação do dano.

Surgem, assim, as noções de dano-evento e dano-prejuízo. O primeiro trata-se da própria lesão a um direito subjetivo ou a um interesse protegido pela norma. O segundo é consequência dessa lesão, podendo ser patrimonial ou não patrimonial e ter por base o

\footnotetext{
${ }^{2}$ PETEFFI DA SILVA, Rafael. Responsabilidade civil pela perda de uma chance: uma análise do direito comparado e brasileiro. 2. ed. São Paulo: Atlas, 2009, p.4.

${ }^{3}$ Embora existam hipóteses em que a existência concreta do dano, na situação específica acaba não se confirmando. É o que ocorre nas situações de dano moral in re ipsa, em que há desnecessidade de comprovação do efetivo surgimento do dano moral no caso concreto, tais como nas controvérsias que envolvem a inscrição indevida do nome do consumidor em cadastros de inadimplentes, conduta esta que, presumidamente, viola a dignidade da pessoa humana. Neste sentido: "a jurisprudência deste Tribunal de Superposição está sedimentada no sentido de que, "nos casos de protesto indevido de título ou inscrição irregular em cadastros de inadimplentes, o dano moral se configura in re ipsa, isto é, prescinde de prova, ainda que a prejudicada seja pessoa jurídica". BRASIL. Superior Tribunal de Justiça. Recurso Especial $n^{\circ}$ 1.698.407-RS, julgado em 16 de outubro de 2017. Relator o Ministro Marco Aurélio Bellizze.

${ }^{4}$ SAVI, Sérgio. Responsabilidade Civil por Perda de uma Chance. 2. ed., São Paulo: Atlas, 2009, p. 104. Confira-se, também: "O sistema de verificação de culpa, calcado em ideias de cunho individualista, evoluiu para um sistema solidarista, com finalidade precípua de manter 'o equilíbrio econômico-jurídico alterado' ante a ocorrência de um prejuízo, e desviou os olhares da responsabilidade civil, antes voltados ao pressuposto da culpa, para o dano". GONDIM, Glenda Gonçalves. A Reparação Civil na Teoria da Perda de uma Chance. São Paulo: Clássica, 2013, p. 21.
} 
indivíduo ou a sociedade como um todo. ${ }^{5}$ A caracterização do fenômeno jurídico do dano, como pressuposto da responsabilidade civil, depende da coexistência do dano-evento e do dano-prejuízo. ${ }^{6}$

A redefinição da responsabilidade civil, como uma reação contra o dano, passou a permitir a reparação de danos em situações sequer impensáveis até então. Foi exatamente nesse contexto que as primeiras demandas em que se pleiteava a reparação pela perda da oportunidade de obtenção de um resultado favorável chegaram aos tribunais franceses. Surgia, então, a chamada teoria da responsabilidade civil pela perda de uma chance.

Em linhas bastante gerais, a teoria da perda de uma chance sugere que aquele que tiver retiradas de seu patrimônio chances sérias e reais de alcançar uma vantagem esperada, ou de evitar um prejuízo já ocorrido, terá direito à reparação do dano decorrido das oportunidades perdidas. ${ }^{7}$

Assim como a própria responsabilidade civil, a perda de chances tem se mostrado um instituto cada vez mais útil e necessário para evitar injustiças. Isso porque a nova lógica de funcionamento das sociedades globais - que envolve a dependência de diversos serviços, prestados por diversos agentes - importa um aumento significativo do risco de se experimentar um prejuízo, graças à ação, culposa ou não, de outrem. Não é à toa que se vê uma quantidade impressionante de demandas relacionadas à responsabilidade civil chegando ao Poder Judiciário todos os dias. E cada vez mais frequentes são os litígios em que se pede a reparação pela oportunidade perdida.

As dificuldades da vida pós-moderna, agravadas pela acirrada competição nos mercados de trabalho, fazem com que os indivíduos deem maior importância à oportunidade. As boas chances de se obter uma vantagem são cada vez mais raras e, não poucas vezes,

\footnotetext{
${ }^{5}$ Destaca-se, aqui, a noção de Antonio Junqueira de Azevedo de dano social: “(...) um ato, se doloso ou gravemente culposo, ou se negativamente exemplar, não é lesivo somente ao patrimônio material ou moral da vítima, mas sim, atinge a toda a sociedade, num rebaixamento imediato do nível de vida da população. Causa dano social. Isto é particularmente evidente quando se trata da segurança, que traz diminuição da tranquilidade social, ou de quebra da confiança, em situações contratuais ou para-contratuais, que acarreta redução da qualidade coletiva de vida". AZEVEDO, Antonio Junqueira de. Por uma nova categoria de dano na responsabilidade civil: o dano social. In: FILOMENO, José Geraldo Brito et al. (Org.). O Código Civil e sua interdisciplinaridade: os reflexos do Código Civil nos demais ramos do Direito. Belo Horizonte: Del Rey, 2004, p. 374.

${ }^{6}$ FLUMIGNAN, Silvano José Gomes. Dano-Evento e Dano Prejuízo. Dissertação de Mestrado - Faculdade de Direito da Universidade de São Paulo, 2009, p. 43.

${ }^{7} \mathrm{O}$ termo chance tem, para os franceses, o significado jurídico de probabilidade de obter lucro ou evitar perda. Em português, a palavra que melhor traduz a ideia de chance é oportunidade. SAVI, Sérgio, p. 3.
} 
consideradas únicas. Assim, a oportunidade de se alcançar um resultado também tem valor significativo - mesmo que em grau menor do que o do próprio resultado.

O estudo da responsabilidade civil pela perda de uma chance é recente no direito pátrio, muito embora esteja ganhando força exponencial. Até o início do novo milênio, não se dedicava ao tema mais do que algumas poucas páginas de tratados de responsabilidade civil. Somente na década passada é que surgiram os primeiros livros especializados sobre o instituto. Desde então, parece que os estudiosos finalmente decidiram dedicar mais tempo e esforços à pesquisa e à análise das chances perdidas. Ao longo da última década, tem sido publicado um número considerável de trabalhos sobre o assunto, dentre livros, teses de graduação, dissertações de mestrado, artigos científicos e, até mesmo, reportagens jurídicas.

No campo jurisprudencial não é diferente. Há alguns anos, era raro se deparar com julgados que abordassem a responsabilidade civil pela perda de uma chance. Atualmente, já são milhares de decisões sobre o tema nos tribunais de todo o país.

Embora o estudo das oportunidades perdidas esteja sendo alvo de verdadeira efervescência doutrinária e jurisprudencial, não são raras as decisões judiciais que, ao aplicar o instituto da perda de uma chance, incorrem em equívocos e confusões diversos. Não é incomum, por exemplo, ver enganos quanto à natureza jurídica dos danos decorrentes da perda de uma chance. ${ }^{8}$

Maior preocupação ainda deve ser direcionada para dois aspectos fundamentais da teoria da perda de uma chance, cuja análise, essencial, acaba sendo suprimida por quem deveria fazê-la, quais sejam, a seriedade da chance perdida e a quantificação do dano.

Para que se chegue à conclusão sobre a possibilidade de conceder indenização pelo dano nascido com a retirada da oportunidade de alcançar vantagem ou de evitar prejuízo do patrimônio da vítima, é necessário ponderar sobre a seriedade da chance perdida.

A doutrina nacional é unânime ao afirmar que as chances perdidas só serão passíveis de indenização se consideradas sérias e reais. O elemento da certeza do dano, tão fundamental para a classificação do dano decorrente da perda de uma chance, também deve ser

\footnotetext{
${ }^{8}$ Como abordado na seção 2.4.2. deste trabalho, certos julgados consultados consideraram a chance perdida como mero agregador de dano moral, independentemente da natureza dos interesses em jogo.
} 
observado para que se verifique se surgirá ou não a obrigação de reparar os prejuízos causados pela oportunidade perdida. Somente se a chance perdida tiver se mostrado suficientemente séria e real é que seu aniquilamento implicará o dever de indenizar. Do contrário, não se terá estabelecido liame causal entre a conduta tida como antijurídica e o dano, de modo que o réu não deverá ser responsabilizado.

As chances devem ser sérias e reais. A doutrina repete esta frase como se ela fosse um verdadeiro mantra, mas poucos autores se dedicaram a tentar definir o que seriam, efetivamente, chances sérias e reais. ${ }^{9}$ Talvez uma definição exauriente não exista, mas certamente é possível traçar certos critérios e parâmetros úteis na tarefa de separar as chances merecedoras de reparação daquelas meras esperanças subjetivas, por demais abstratas, cuja perda não gera dever de indenizar.

Ultrapassada a análise sobre a seriedade da chance perdida, surge novo problema: a quantificação do dano decorrente da perda de uma chance. Raros são os casos em que o julgador apresenta justificativas técnicas para chegar ao quantum indenizatório. No mais das vezes, dedica-se poucas linhas para, sem explicação satisfatória, condenar o ofensor ao pagamento de um valor fixado de maneira indesejavelmente aleatória.

A primeira premissa a ser estabelecida é a de que o valor a ser indenizado pelo dano decorrente da perda de uma chance será sempre menor do que o valor atribuído ao resultado futuro - do contrário, a distinção da perda da chance e da perda do próprio resultado vantajoso não faria sentido.

O método de quantificação do dano mais difundido no Brasil é o da proporcionalidade, pelo qual se multiplica o percentual da chance perdida pelo valor do dano final para se obter o valor da oportunidade em questão. A experiência norte-americana, pouco estudada no Brasil, revela diversas outras propostas, cada uma com vantagens e desvantagens se comparadas com a forma tradicional de aferição do quantum debeatur.

O aprofundamento do estudo destes dois aspectos - seriedade das chances perdidas e quantificação do dano -, tão importantes para que se dê uma melhor aplicação da teoria da

\footnotetext{
${ }^{9}$ Os debates mais profundos com os quais se teve contato foram travados por autores norte-americanos, que serão bastante referenciados no terceiro capítulo desta dissertação. Na doutrina nacional, não se pode deixar de referenciar Rafael Peteffi da Silva (PETEFFI DA SILVA, Rafael, 2009). No direito português, destaca-se a obra de Rute Teixeira Pedro (PEDRO, Rute Teixeira. A Responsabilidade Civil do Médico: Reflexões Sobre a Noção da Perda de Chance e a Tutela do Doente Lesado. Coimbra: Coimbra Editora, 2008).
} 
perda de uma chance, mostra-se bastante pertinente, oportuno, e até mesmo desejável. A verdade é que, no atual momento, qualquer estudo que se proponha a dar enfoque para as dificuldades no uso do instituto da perda de uma chance vem em excelente hora. 


\section{CONCLUSÃO}

As chances perdidas são indenizáveis. Esta é uma afirmação tranquila de se fazer na atualidade. A teoria da perda de uma chance, cujas primeiras referências foram feitas há cerca de um século na Inglaterra, na França e nos Estados Unidos, já está suficientemente madura para que os estudiosos deixem de se preocupar com as justificativas para que as cortes de justiça ao redor do mundo reconheçam a possibilidade de conferir indenização pelo dano decorrente das chances perdidas, e passem a centrar os esforços na identificação dos problemas práticos decorrentes da aplicação do instituto e na busca por soluções que melhorem o seu uso.

Buscar contribuir com o aprimoramento da aplicação da perda de uma chance sempre foi o objetivo da presente dissertação, mais especificamente quanto aos dois aspectos mais nebulosos do instituto: a seriedade da chance perdida e a quantificação do dano.

Mas, ainda que, de certa forma, de modo preambular às grandes discussões travadas neste estudo, foram alcançadas algumas conclusões importantes. Foi visto que há duas modalidades de perda da chance: (i) a clássica, que engloba os casos de perda da chance de alcançar uma vantagem pretendida no futuro; e (ii) a de evitar a ocorrência de um resultado danoso já concretizado, que engloba, dentre outros, os casos de perda da chance na área médica. Quanto ao primeiro tipo, nunca houve divergências doutrinárias, mas, quanto à segunda modalidade, ainda há bastante dissenso entre os estudiosos do tema.

De todas as correntes existentes, a teoria unitária é a que melhor resolve o problema. Assim como nos casos clássicos, nas situações de perda da chance de evitar um dano já ocorrido, está-se diante de um dano autônomo em relação ao dano final. No caso de perda da chance médica, por exemplo, não se busca indenizar parcialmente pela morte, mas sim integralmente pela perda da chance de sobrevivência, que é um interesse jurídico diverso da própria vida. A relação de causalidade entre a conduta lesiva e o dano final é impossível, mas estabelecer o liame causal entre o ato danoso e o dano da perda da chance é perfeitamente factível.

Também há certa polêmica quanto à natureza jurídica do dano da perda de uma chance. Polêmica esta que não deveria existir, pois é completamente inviável equiparar a chance perdida ao lucro cessante, em razão da incerteza de ocorrência do resultado final 
pretendido nos casos de perda de uma chance, enquanto que nas hipóteses de lucros cessantes, a ocorrência do resultado final é certo, só não se conhece sua exata extensão.

É evidente que a perda e uma chance, tratando-se de dano material, deve ser enquadrada como dano emergente, em razão de a chance ser um bem integrante do patrimônio da vítima, revestido de valor econômico. A eliminação da chance é, repita-se, um dano independente do dano final, consistente na eliminação da própria vantagem pretendida.

Há quem defenda que a chance perdida deveria ser alçada a uma nova categoria de dano, ao lado do lucro cessante e do dano emergente, mas tal providência não é necessária, uma vez que é plenamente viável enquadrar a chance perdida como dano emergente, ainda que algumas características suas destoem da definição mais clássica desta modalidade de dano.

O dano decorrente da perda de uma chance também pode ter natureza extrapatrimonial. A questão é simples: a natureza da chance perdida será a mesma da do dano final. Se a vantagem pretendida ou o resultado que se queria evitar tinham caráter patrimonial, também o terá a chance perdida respectiva. Se, ao contrário, o dano final é extrapatrimonial, também o será o dano decorrente da chance perdida.

Ressalvada sua relevância , os pontos discutidos no segundo capítulo servem como suporte necessário para a correta compreensão dos dois capítulos centrais deste trabalho, que tratam, respectivamente, da seriedade das chances perdidas e da quantificação do dano delas decorrente.

\section{Duas são as questões principais que se propôs a responder: (i) o que são chances sérias e reais? e (ii) como quantificar o dano decorrente das chances perdidas?}

A primeira resposta passa pela distinção entre a perda de uma chance e a criação de riscos. A mera criação de riscos de ocorrência de um resultado danoso no futuro não pode gerar dever de indenizar. Somente com a eventual concretização do dano representado pelo risco é que a vítima terá uma pretensão reparatória em face do criador do risco e, consequentemente, do prejuízo indenizável.

Para ser indenizada, a chance perdida deve ter sido séria e real. Esta frase ecoa em todos os livros, artigos e trabalhos acadêmicos que abordam a perda de uma chance e em todos os julgados que decidem sobre casos envolvendo chances perdidas. A chance indenizável não 
será aquela que se traduzir em mera possibilidade hipotética, mas tão somente aquela que significar uma probabilidade concreta de se alcançar o resultado final.

Surge, então, a natural pergunta acerca da existência de um percentual mínimo para que uma chance seja séria e real. A resposta deve ser negativa. O estabelecimento de uma linha divisória estática entre os casos que devem merecer reparação e aqueles nos quais as vítimas se verão desamparadas contribui para a criação de injustiças. O magistrado deverá sempre analisar o caso concreto para verificar se a oportunidade perdida era ou não idônea, não se prendendo a percentuais apriorísticos, embora possa se valer das provas estatísticas para chegar à sua convicção.

Outra afirmação repetida à exaustão é a de que, para ser indenizada, a chance deve ter sido perdida de forma definitiva. Vale dizer, a conduta antijurídica do ofensor deve ter sido responsável por ceifar completamente a probabilidade de a vantagem pretendida ser alcançada ou de o resultado danoso ser evitado, de modo que surja o dano final. Haverá casos, contudo, em que a destruição de uma chance individualizada não importará na perda definitiva da vantagem almejada, de modo que o ofensor não poderá, então, ser condenado.

Por outro lado, ainda que destruída a chance, pode ser que, no futuro, em outro contexto, surja nova oportunidade, mas que não tenha o mesmo valor que a chance originalmente destruída. Assim, o caráter de definitividade não deve ser avaliado de forma abstrata, mas sempre levando em consideração o cenário que se concretizou, bem como a importância que aquela chance perdida representava para a vítima, naquele momento específico.

Igualmente importante será observar o lapso temporal entre o evento tido como danoso e o momento em que a vantagem almejada poderia vir a ser alcançada pela vítima. Quanto maior for este decurso de tempo, menor será a seriedade da chance perdida, em virtude do aumento da possibilidade de que outros fatores tenham influenciado na não obtenção do resultado pretendido, dificultando o estabelecimento do nexo de causalidade.

O recurso à estatística é uma ferramenta crucial para a mensuração da seriedade das chances perdidas, mas não se pode confiar cegamente nos dados estatísticos. Sempre que possível, será preciso transformar uma chance estatística em uma chance pessoal, por meio do exame das particularidades do caso concreto, incluindo as características pessoais da vítima, nas situações em que elas puderem influir de alguma maneira. 
Os elementos de cada caso servirão para confirmar, potencializar, enfraquecer ou desmistificar os dados estatísticos apontados. Por um lado, quando a estatística for a única ferramenta disponível, não se deve simplesmente descartar este meio de prova. Por outro lado, a estatística não pode ser considerada irrefutável diante da existência de outros elementos probatórios.

Ainda no tocante à seriedade da chance perdida, embora seja plenamente admissível que não se tenha certeza quanto à realização do resultado final pretendido - aliás, esta é uma premissa para aplicação da perda de uma chance -, deve haver certeza quanto à existência da própria chance. Exatamente por isso, não se pode admitir a combinação de probabilidades de primeira e segunda ordens, nem tampouco a aplicação do princípio da conjunção no momento de estabelecimento do nexo causal entre a conduta tida como danosa e o dano decorrente da perda da chance.

A resposta à segunda questão, ou seja, encontrar o modo mais adequado de atribuição de valor à indenização pelo dano oriundo da chance perdida é tarefa, ao mesmo tempo, muito relevante e igualmente difícil. Deve-se partir da máxima de que o valor do dano consistente na perda da chance sempre será menor do que o valor do dano final.

Embora o método de quantificação do dano denominado proportional approach seja o mais adotado em todos os ordenamentos jurídicos estudados, ele não será o mais justo nos casos de perda da chance de evitar um dano já ocorrido. A fórmula elaborada por Paul Speaker e o método do risco atribuído, por outro lado, logram êxito em chegar a um resultado satisfatório, tanto nos casos clássicos, quanto nas hipóteses de perda da chance de evitar um resultado negativo.

Assim, a forma mais adequada de quantificação do dano decorrente da perda de uma chance passa pela observação de um sistema bifásico, que abrange duas etapas: (i) primeiro, afere-se o percentual das chances perdidas por meio da fórmula de Paul Speaker ou da fórmula do risco atribuído e; na sequência, (ii) multiplica-se este percentual pelo valor da própria vantagem definitiva que a vítima objetivava alcançar.

Mas a quantificação do dano não deve se resumir à aplicação cega de fórmulas matemáticas estáticas. Não se pode virar as costas para as particularidades do caso concreto, especialmente nos casos mais complexos, em que não se tem à disposição todos os fatores necessários para a aplicação das fórmulas matemáticas, de modo que o juiz 
deverá fazer uso da sua discricionariedade, para, apoiado nos princípios gerais do Direito, nas normas legais aplicáveis ao caso, nas condições individualizadas da situação concreta e na sua experiência como julgador, alcançar o quantum indenizatório mais justo na situação concreta.

Quando não houver informações e provas suficientes para uma quantificação técnica do dano, então o magistrado poderá recorrer, subsidiariamente, à avaliação equitativa do dano, desde que seu raciocínio seja meticulosamente fundamentado na decisão.

Estas foram as principais conclusões alcançadas ao longo desta dissertação. Buscou-se estabelecer o maior número de critérios e parâmetros auxiliadores na árdua incumbência de se verificar a seriedade da chance perdida e proceder à mais justa quantificação do dano.

Como já alertado, estes dois aspectos, tão relevantes para uma correta aplicação do instituto da perda de uma chance, não podem ser negligenciados pelas decisões judiciais. $\mathrm{Na}$ generalidade dos casos, as sentenças e acórdãos são fundamentados em lições doutrinárias valiosas, mas que raramente são efetivamente aplicadas quando da mensuração da idoneidade da chance perdida e da aferição do valor da indenização. No mais das vezes, estas duas etapas são resolvidas de forma superficial, como acontece também, por vezes, nos casos de atribuição de valor aos danos extrapatrimoniais.

A esperança é que, com um debate doutrinário acalentado sobre os pontos mais delicados da teoria da perda de uma chance e com o estabelecimento de definições, bases, critérios e limites envolvendo a seriedade das chances perdidas e a quantificação do dano, o Poder Judiciário tenha mais parâmetros e elementos para chegar a resultados mais justos e adequadamente fundamentados nas decisões envolvendo o tema. O incentivo da doutrina já exerceu papel fundamental na aceitação do instituto das chances perdidas pelos tribunais pátrios e, felizmente, o mesmo acontecerá quanto à sua aplicação mais técnica. 


\section{BIBLIOGRAFIA}

AAGAARD, Todd S. Identifying and Valuing the Injury in Lost Chance Cases. Michigan Law Review, v. 96, p. 1335, 1997-1998.

ALVIM, Agostinho. Da Inexecução das Obrigações e suas Consequências. 5 ed., São Paulo: Saraiva, 1980.

ALVIM, Pedro. O Contrato de Seguro. 3 ed., Rio de Janeiro: Forense, 2001.

AMARAL, Ana Cláudia Corrêa Zuin Mattos do. Responsabilidade civil pela perda da chance: Natureza jurídica e quantificação do dano. Curitiba: Juruá, 2015.

AGUIAR DIAS, José de. Da Responsabilidade Civil. 10 ed. revista e aumentada, Rio de Janeiro: Forense, 1997. 11ed., Rio de Janeiro: Renovar, 2006.

AZEVEDO, Antonio Junqueira de. Por uma nova categoria de dano na responsabilidade civil: o dano social. In: FILOMENO, José Geraldo Brito et al. (Org.). O Código Civil e sua interdisciplinaridade: os reflexos do Código Civil nos demais ramos do Direito. Belo Horizonte: Del Rey, 2004.

BOCCHIOLA, Maurizio. Perdita di una "chance" e certezza del danno. In Rivista Trimestrale di Diritto e Procedura Civile, anno XXX, p. 55-102, 1976.

BRENNWALD, Stephen F. Proving Causation in "Loss of a Chance" Cases: a Proportional Approach. Catholic University Law Review, v. 34, p. 747, 1984-1985.

BRIZ, Jaime Santos. Derecho de Daños. Madrid: Edit. Revista de Derecho Privado, 1963.

BRUER, Robert S. Loss of a Chance as a Cause of Action in Medical Malpractice Cases. Missouri Law Review, v. 59, nº 4, p. 969, fall 1994.

CARNAÚBA, Daniel Amaral. Responsabilidade Civil pela Perda de uma Chance - A Álea e a Técnica. São Paulo: Método, 2013, p. 33-34. 
CARNEY, Dionne R. Smith v. State of Louisiana, Department of Health and Hospitals: Loss Chance of Survival: The Valuation Debate. Louisiana Law Review, v. 58:1, p. 339, Fall, 1997.

CARVALHO, João Eduardo Braz de. Responsabilidade civil por perda de uma chance: Análise doutrinária e jurisprudencial. Dissertação de Mestrado - Faculdade de Direito da Universidade de São Paulo, 2016.

CARVALHO FILHO, Milton Paulo de. Indenização por Equidade no Novo Código Civil. 2. ed. São Paulo: Atlas, 2013.

CARVALHO SANTOS, J.M. de. Código Civil Interpretado. 2 ed., Rio de Janeiro: Freitas Bastos, 1938. v. 21.

CAVALIERI FILHO, Sergio. Programa de Responsabilidade Civil. 9. ed. revista e ampliada, São Paulo: Atlas, 2010.

CHINDEMI, Domenico. Il Danno da Perdita di Chance. 2. ed. Milão: Giuffrè Editore, 2010.

COUTO E SILVA, Clóvis do. O conceito de dano no direito brasileiro e comparado. In: FRADERA, Vera Maria Jacob de (Org.). O Direito Privado Brasileiro na Visão de Clóvis do Couto e Silva. Porto Alegre: Livraria do Advogado, 1997.

CRUZ, Gisela Sampaio da. O problema do nexo causal na responsabilidade civil. Rio de Janeiro: Renovar, 2005.

DE CUPIS, Adriano. Il Danno. Teoria generalle della responsabilità civile. 2 ed. Vol I. Milano: Dott A. Giufrè Editore, 1966.

DIAS, Sérgio Novais. Responsabilidade civil do advogado na perda de uma chance. São Paulo: LTr. 1999.

DINIZ, Maria Helena. Curso de Direito Civil Brasileiro, v. 7, Responsabilidade Civil. 25 ed., São Paulo: Saraiva, 2012.

ELLIS, Lori R. Loss of a chance as technique: toeing the line at fifty percent. Texas Law Review, 72, p. 369, 1993. 
FEOLA, Maria. Nesso di causalitá e perdita di chances nella responsabilità civile del professionista forense. Rivista Critica del Diritto Privato, p. 151, 2004.

FÉROT, Alice. The Theory of Loss of Chance: Between Reticence and Acceptance. Florida International University Law Review, v. 8, p. 591, Spring, 2013.

FISCHER, David A. Tort recovery for loss of a chance. Wake Forest Law Review, p. 605, Fall, 2001.

FLUMignAN, Silvano José Gomes. Dano-Evento e Dano Prejuízo. Dissertação de Mestrado - Faculdade de Direito da Universidade de São Paulo, 2009.

FRADERA, Vera Maria Jacob de. A responsabilidade civil dos médicos. Revista da Ajuris, a. 19, n. 55 , p. 116-139, jul. 1992.

FRASCA, Ralph, Loss of Chance Rules and the Valuation of Loss of a Chance Damages. Journal of Legal Economics, v. 15, nº 2, 2008-2009, p. 91.

GALLO, Paolo. Diritto Privato. Torino: Giappichelli Editore, 2006.

GOMES, Orlando. Contratos. 26ª ed., Rio de Janeiro: Forense, 2008.

GONDIM, Glenda Gonçalves. A Reparação Civil na Teoria da Perda de uma Chance. São Paulo: Clássica, 2013.

GONZÁLEZ, Clara I. Asua. Pérdida de Oportunidad en la Responsabilidad Sanitaria. 1. ed., Navarra: Editorial Aranzadi, 2008.

HAMER, David. 'Chance Would be a Fine Thing': Proof of Causation and Quantum in an Unpredictable World. Melbourne University Law Review, v. 23, p. 557, 1999.

HIGA, Flávio da Costa. A perda da chance no direito do trabalho. Dissertação de Mestrado - Faculdade de Direito da Universidade de São Paulo, 2011.

HOUAISS, Antônio. Grande Dicionário Houaiss da Língua Portuguesa. Disponível para assinantes UOL em http://houaiss.uol.com.br.

JAFET, Danilo Haddad. Hipóteses de aplicação da teoria da responsabilidade civil pela perda de uma chance no Direito de Família. Revista Jurídica Luso Brasileira da Faculdade 
de Direito da Universidade de Lisboa, Ano 2, $\mathrm{n}^{\circ}$ 1, 2016, p. 19-54. Disponível em http://www.cidp.pt/publicacoes/revistas/rjlb/2016/1/2016_01_0019_0054.pdf

JANSEN, Nils. The Idea of a Lost Chance. Oxford Journal of Legal Studies, v. 19, 1999, p. 271-296.

JOURDAIN, Patrice. La perte d'une chance, même faible, est indmnisable!. Revue Trimestrielle de Droit Civil, n. 2, p. 380, 2013.

KADANE, Joseph; STERN, Rafael. Compensating for the Loss of a Chance. Pittsburgh, 2014. Disponível em https://arxiv.org/abs/1412.1501.

KFOURI NETO, Miguel. Responsabilidade civil dos hospitais. 2 ed. São Paulo: Revista dos Tribunais, 2015.

KING JR., Joseph H. Causation, Valuation, and Chance in Personal Injury Torts Involving Preexisting Conditions and Future Consequences. Yale Law Journal, v. 90, p. 1353, 19801981.

. "Reduction of Likelihood" Reformulation and Other Retrofitting od the Loss-of-aChance Doctrine. University of Memphis Law Review, v. 28, p. 491, 1997-1998.

LE TOURNEAU, Philippe. La Responsabilité Civile. 2 ed., Paris: Dalloz, 1976.

LOEVINGER, Lee. Jurimetrics: The Next Step Forward. Minesotta Law Review Journal of the State Bar Association, v. 33, p. 455, 1949.

MAKDISI, John, Proportional Liability: a comprehensive rule to apportion Tort Damages based on probability. North Caroline Law Review, v. 67, p. 1063, 1988-1989.

MANION, J. Brian. Damages for Increased Risk of Future Injury: Can Illinois Courts See Into the Future? Dillon v. Evanston Hospital, 771 n.e.2d 357 (ill. 2002). South Illinois University Law Journal, v. 28, p. 201, 2004.

MARTINS-COSTA, Judith Hofmeister. Comentários ao Novo Código Civil, v. V, tomo II. Rio de Janeiro: Forense, 2003.

MCKAY, Clare. Concurrent Liability in Claims for Loss of a Chance of a Better Medical Outcome. Torts Law Journal, v. 20:1, p. 29, 2012. 
MELO, Raimundo Simão de. Indenização pela perda de uma chance. Boletim Jurídico, Uberaba/MG, a. 5, no 224. Disponível em:

http://www.boletimjuridico.com.br/ doutrina/texto.asp?id=1785.

MONATERI, Pier Giuseppe; GIANTI, Davide; CINELLI, Luca Siliquini. Danno $e$ Risarcimento. Torino: G. Giappichelli Editore, 2013.

MORSELlO, Marco Fábio. O Nexo Causal e suas Distintas Teorias: Apreciações Críticas. Revista do Instituto dos Advogados de São Paulo, v. 10, n. 19, p. 211, jan./jun. 2007.

MULHOLLAND, Caitlin Sampaio. A responsabilidade civil por presunção de causalidade. Rio de Janeiro: GZ Ed., 2010.

NOAH, Lars. An Inventory of Mathematical Blunders in Applying the Loss-of-a-ChanceDoctrine. The Review of Litigation, v. 24:2, p. 369, April, 2005.

NORONHA, Fernando. Direito das Obrigações. São Paulo: Saraiva, 2003.

NUNES, Marcelo Guedes. Palavras do Presidente. Disponível em: http://abjur.org.br/quem-somos-palavra-do-presidente.php.

PEDRO, Rute Teixeira. A Responsabilidade Civil do Médico: Reflexões Sobre a Noção da Perda de Chance e a Tutela do Doente Lesado. Coimbra: Coimbra Editora, 2008.

PEREIRA, Caio Mário da Silva. Responsabilidade Civil. 9 ed. revista, Rio de Janeiro: Forense, 1999.

PETEFFI DA SILVA, Rafael. Responsabilidade Civil pela Perda de uma Chance: uma Análise do Direito Comparado e Brasileiro. 2. ed. São Paulo: Atlas, 2009.

. A responsabilidade pela perda de uma chance, rico exemplo de circulação de modelos doutrinários e jurisprudenciais. In MARTINS-COSTA, Judith (Org.). Modelos de direito privado. 1 ed., São Paulo: Marcial Pons, 2014.

POLIDO, Walter. Seguro de Responsabilidade Civil - Riscos Profissionais (RCP). Disponível em https://www.google.com.br/url?sa=t\&rct=j\&q=\&esrc=s\&source=web\&cd=1\&ved=0ahUK 
EwjYkK3n0JPUAhVDEpAKHfJ5BTkQFghPMAA\&url=http\%3A\%2F\%2Fwww.polidoco nsultoria.com.br\%2Ftextos\%2FSeguros\%2520de\%2520Responsabilidade\%2520Civil\%25 20Profissional.doc\&usg=AFQjCNEjiVFgh01_4FVvLr06eEMCGbXSsw

POSSAMAI, Fábio José. O seguro de responsabilidade civil profissional - advogados e a chance perdida indenizável. 13/12/2016, p. 4. Disponível em http://poletto.adv.br/oseguroderesponsabilidadecivilprofissionaladvogadoseachanceperdida indenizavel/

PUOLI, José Carlos Baptista. O ônus da prova e sua distribuição dinâmica no novo Código de Processo Civil. In O Novo Código de Processo Civil: questões controvertidas. Vários autores. São Paulo: Atlas, 2015.

REALE, Miguel. Questões de Direito Público. São Paulo: Saraiva, 1997.

RHEE, Robert J. Loss of a Chance, Probabilistic Cause, and Damage Calculations: the Error in Matsuyama v. Birnbaum and the Majority Rule of Damages in Many Jurisdictions More Generally. 1 Suffolk University Law Review Online, v. 39, 2013. Disponível em: http://scholarship.law.ufl.edu/facultypub/470.

RODRIGUES JR., Otavio Luiz. Reforma dos Códigos Deve Ser Democrática e Pluralista. Disponível em: http://www.conjur.com.br/2013-jan-02/direito-comparado-reformacodigos-democratica-pluralista.

ROCHA, Nuno Santos. A Perda da Chance como uma Nova Espécie de Dano. Coimbra: Almedina, 2015.

ROSATI, Jack. Causation in Medical Malpractice: a Modified Valuation Approach. Ohio State Law Journal, v. 50:2, p. 469, 1989.

SANTOS, Antonio Jeová. Dano Moral Indenizável. 4 ed., São Paulo: Revista dos Tribunais, 2003.

SAROYAN, Zaven T. The Current Injustice of the Loss of Chance Doctrine: An Argument for a New Approach to Damages. Cumberland Law Review, v. 33, p. 15, 2002-2003.

SAVI, Sérgio. Responsabilidade Civil por Perda de uma Chance. 2. ed., São Paulo: Atlas, 2009. 
SCHREIBER, Anderson. Novos Paradigmas da Responsabilidade Civil. 2 ed., São Paulo: Atlas, 2009.

SECUNDA, Paul M. A Public Interest Model for Applying Lost Chance Theory to Probabilistic Injuries in Employment Discrimination Cases. Wisconsin Law Review, p. $747,2005$.

SERPA LOPES, Miguel Maria de. Curso de Direito Civil, v. II, Obrigações em Geral. 5 ed., Rio de Janeiro: Freitas Bastos, 1989.

SEVERO, Sérgio. Os Danos Extrapatrimoniais. São Paulo: Saraiva, 1996.

SILVA, De Plácido e. Vocabulário Jurídico. v. 4, 5. ed., Rio de Janeiro: Forense, 1978.

SILVEIRA, Fabiano Feijó; ZABALA, Filipe Jaeger. Jurimetria: Estatística Aplicada ao Direito. Revista Direito e Liberdade, v. 16:1, p. 73, janeiro/abril, 2014.

SPEAKER, Paul. The Application of the Loss of a Chance Doctrine in Class Actions. The Review of Litigation, v. 21, p. 345, 2002.

STOCO, Rui. Tratado de Responsabilidade Civil. 8 ed., São Paulo: Revista dos Tribunais, 2011.

TEPEDINO, Gustavo. Temas de Direito Civil, t. 2. Rio de Janeiro: Renovar, 2006.

TIJMS, Henk. Understanding Probability. 3 ed., Cambridge: Cambridge University Press, 2012.

TZIRULNIK, Ernesto; CAVALCANTI, Flávio de Queiroz B.; PIMENTEL, Ayrton. $O$ contrato de seguro de acordo com o código civil brasileiro. 3 ed., São Paulo: Roncarati, 2016.

VENOSA, Sílvio de Salvo. Direito Civil, v. 4, Responsabilidade Civil. 7 ed., São Paulo: Atlas, 2007.

VINEY, Geneviève; JOURDAIN, Patrice. Les conditions de la responsabilité. In GHESTIN, Jacques (Dir.). Traité de droit civil. 3 ed., Paris: LGDJ, 2006. 
WEISZFLOG, Walter. Michaelis Moderno Dicionário da Língua Portuguesa. Disponível em: http://michaelis.uol.com.br.

WESTCOTT, G. A. Calculating Loss of Opportunity for Career Advancement: Clearing the Clouds in the Crystal Ball. The Advocates' Quarterly, v. 4:3, Ontario, p. 268, 1983.

WILlGING, Kevin Joseph. Falcon v. Memorial Hospital: A Rational Approach to Lossof-Chance Tort Actions. Journal of Contemporary Health Law \& Policy, v. 9, p. 545, 1993. WURDEMAN, Matthew. Loss-of-Chance Doctrine in Washington: from Herskovits to Mohr and the Need for Clarification. Washington Law Review, v. 89, p. 603, 2014.

ZANNONI, Eduardo A. El daño en la responsabilidad civil. 2. ed. Buenos Aires: Editorial Astrea, 1993. 


\section{ÍNDICE REMISSIVO DOS PRINCIPAIS JULGADOS CITADOS}

- Agravo Regimental no 4.364-SP (BR) - perda da chance em licitação: p. 30

- Apelação no 598069996/TJRS (BR) - perda da chance na área médica: p. 29

- Apelação n ${ }^{\circ}$ 591064837/TJRS (BR) - perda da chance de vitória judicial: p. 29, n.r. 54

- Apelação no 415.837-4/TJPR (BR) - perda da chance na área médica: p. 63

- Apelação Cível no 9213233-15.2009.8.26.0000/TJSP (BR) - perda da chance como agregador de dano moral: p. 75

- Apelação Cível no 9101783-67.2009.8.26.0000/TJSP (BR) - perda da chance como agregador de dano moral: p. 76, n.r. 178

- Apelação Cível no 9101783-67.2009.8.26.0000/TJSP (BR) - perda da chance como agregador de dano moral: p. 76, n.r. 178

- Apelação Cível no 2012.002661-6/0000-00/TJMS (BR) - perda da chance como agregador de dano moral: p. 76, n.r. 178

- Apelação Cível no 1947104-75.2006.8.13.0105/TJMG (BR) - análise minuciosa sobre a seriedade da chance perdida: p. 100, n.r. 253

- Apelação Cível no 70034240721/TJRS (BR) - análise minuciosa sobre a seriedade da chance perdida: p. 100, n.r. 253

- Apelação Cível no 70016523805/TJRS (BR) - análise sobre a definitividade da chance perdida: p. 102

- Apelação no 0020027-26.2005.8.19.0001/TJRJ (BR ) - aplicação do método bifásico para arbitramento de indenização por dano moral: p. 171, n.r. 397

- Biondo v. City of Chicago (EUA) - perda da chance de promoção no emprego: p. 140

- Boody v. United States (EUA) - perda da chance na área médica: p. 134, n.r. 314

- Caso do Show do Milhão (BR) - perda da chance de vencer competição em programa televisivo: p. 116-120, 175

- Caisse Commerciale de Limoges v. Rives (FR) - perda da chance de vitória judicial : p. 17

- Cass. 19 novembre 1983, n. 6906 (IT) - perda da chance de ser admitido como empregado: p. 19

- Cass. civ. 1ère 14 décembre 1965, JCP 1966 II 14753, D 1966 p. 453 (FR) - perda da chance na área médica: p. 53

- Cass. civ. 2e, 1er julliet, 2010, 09-15.594 (FR) - discussão sobre percentual mínimo da chance indenizável: p. 98, n.r. 246 
- Cass. civ. 2e, 9 novembre, 1983, 82-12.427 (FR) - análise sobre a seriedade da chance em virtude do lapso temporal decorrido: p. 105

- Chaplin v. Hicks (ING) - perda da chance de vencer concurso: p. 18

- Collet v. Smith and Middlesbrough (ING) - perda da chance de ascender na carreira futebolística: p. 106

- Cooper v. Sisters of Charity (EUA) - perda da chance na área médica: p. 34

- Corte di Cassazione, sezione III civile; sentenza 4 marzo 2004, n. 4400 (IT) reconhecimento do valor patrimonial da chance: p. 71

- Davies v. Taylor (ING) - discussão sobre percentual mínimo da chance indenizável: p. 96

- Delaney v. Cade (EUA) - abordagem do método da discricionariedade: p. 162, n.r. 377;

p. 167 , n.r. 390

- Dillon v. Evanston Hospital (EUA) - indenização pela criação de risco: p. 85

- Donnini v. Ouano (EUA) - perda da chance na área médica: p. 36, n.r. 83

- Doll v. Brown (EUA) - perda da chance de promoção empregatícia: p. 22, n.r. 28

- Embargos de Declaração no Agravo Regimental no Agravo de Instrumento ${ }^{\circ}$ 1.196.957-

DF (BR) - perda da chance de vencer sorteio: p. 115, n.r. 277; p. 144; p. 170, n.r. 396

- Falcon v. Memorial Hospital (EUA) - perda da chance na área médica: p. 143

- Gardner v. National Bulk Carriers, Inc. (EUA) - perda da chance de resgate marítimo: p.

21

- Grimaldi v. Marnier (FR) - perda da chance de adquirir imóvel: p. 17.

- Hameed v. International Assn. of Bridge, Structural and Ornamental Iron Workers (EUA) - perda da chance de admissão em emprego: p. 152

- Harding v. Deiss (EUA) - erro na avaliação da chance na área médica: p. 136, n.r. 318

- Harp v. Illinois Central Gulf Railroad Co. (EUA) - indenização pela criação de risco: p. 92

- Herskovits v. Group Health Cooperative of Puget Sound (EUA) - perda da chance na área médica: p. 25, 110, 151-155

- Hotson v. East Berkshire Health Authority (ING) - perda da chance na área médica (análise sobre chances estatística): p. 111, 124

- Kallenberg v. Beth Israel Hospital (EUA) - perda da chance na área médica: p. 36

- Mange v. Unicorn Press (EUA) - perda da chance de vencer competição: p. 22, n.r. 28

- Matsuyama v. Birbaum (EUA) - perda da chance na área médica: p. 156

- Mauro v. Raymark Industry (EUA) - indenização pela criação de risco: p. 88

- Miller v. Allstate Ins. Co. (EUA) - perda da chance de vitória judicial: p. 22, n.r. 28 
- Perez v. Las Vegas Medical Center (EUA) - discussão sobre percentual mínimo da chance indenizável: p. 96, n.r. 237

- Petriello v. Kalman (EUA) - indenização pela criação de risco: p. 84

- Schwegel v. Goldberg (EUA) - indenização pela criação de risco: p. 84

- Sellars v. Adelaide Petroleum N.L. and Others (AUS) - perda da chance no campo empresarial: p. 121

- Shinholster v. Annapolis Hosp. (EUA) - erro na avaliação da chance na área médica: p. 136, n.r. 318

- Smith v. State Department of Health and Hospitals (EUA) - aplicação do método da discricionariedade: p. 164

- Recurso Especial n ${ }^{\circ}$ 1.254.141 (BR) - perda da chance na área médica: p. 63

- Recurso Especial no 1.698.407-RS (BR) - dano moral presumido: p. 12, n.r. 3

- Recurso Especial no 1.190.180 (BR) - perda da chance como terceiro gênero de dano material: p. 72, n.r. 173; p. 184, n.r. 426

- Recurso Especial no 821.004 (BR) - perda da chance como terceiro gênero de dano material: p. 73, n.r. 173

- Recurso Especial no 1159867-MG (BR) - requisitos para concessão de indenização por dano moral: p. 78, n.r. 182

- Recurso Especial n ${ }^{\circ}$ 1079185-MG (BR) - análise da natureza jurídica da perda da chance:

p. 80

- Recurso Especial n 1.615.971-DF (BR) - análise sobre as teorias da causalidade: p. 122, n.r. 292

- Recurso Especial $n^{\circ}$ 1.638.240-MG (BR) - análise sobre as teorias da causalidade: p. 122, n.r. 292

- Recurso Especial n ${ }^{\circ}$ 1.637.611-RJ (BR) - análise sobre as teorias da causalidade: p. 122, n.r. 292

- Recurso Especial nº 1.152.541-RS (BR ) - aplicação do método bifásico para arbitramento de indenização por dano moral: p. 171, n.r. 397; p. 174, n.r. 407

- Recurso Cível no 71001196195/TJRS (BR) - recurso à equidade para quantificar o dano decorrente da perda da chance: p. 175, n.r. 412

- Tran v. Lam (AUS) - perda da chance na área médica: p. 127

- Wollen v. DePaul Health Center (EUA) - perda da chance na área médica (análise sobre chances estatística): p. 112 
- Zinnel v. United States Shipping Board Emergency Fleet Corp. (EUA) - perda da chance de resgate marítimo: p. 20 